\title{
Comparison of soil moisture fields estimated by catchment modelling and remote sensing: a case study in South Africa
}

\author{
T. Vischel ${ }^{1, *}$, G. G. S. Pegram ${ }^{1}$, S. Sinclair ${ }^{1}$, W. Wagner $^{2}$, and A. Bartsch ${ }^{2}$ \\ ${ }^{1}$ Civil Engineering Programme, University of KwaZulu-Natal, Durban 4041, South Africa \\ ${ }^{2}$ Institute of Photogrammetry and Remote Sensing, Vienna University of Technology, Austria \\ *now at: Laboratoire d'étude des Transferts en Hydrologie et Environnement (UMR 5564), 38000 Grenoble, France
}

Received: 28 June 2007 - Published in Hydrol. Earth Syst. Sci. Discuss.: 12 July 2007

Revised: 11 April 2008 - Accepted: 11 April 2008 - Published: 23 May 2008

\begin{abstract}
The paper compares two independent approaches to estimate soil moisture at the regional scale over a $4625 \mathrm{~km}^{2}$ catchment (Liebenbergsvlei, South Africa). The first estimate is derived from a physically-based hydrological model (TOPKAPI). The second estimate is derived from the scatterometer on board the European Remote Sensing satellite (ERS). Results show a good correspondence between the modelled and remotely sensed soil moisture, particularly with respect to the soil moisture dynamic, illustrated over two selected seasons of 8 months, yielding regression $R^{2}$ coefficients lying between 0.68 and 0.92 . Such a close similarity between these two different, independent approaches is very promising for (i) remote sensing in general (ii) the use of hydrological models to back-calculate and disaggregate the satellite soil moisture estimate and (iii) for hydrological models to assimilate the remotely sensed soil moisture.
\end{abstract}

\section{Introduction}

The content of water in the first active metres of soil plays a central role in the regulation of the hydraulic and energy transfers between the soil, the surface and the atmosphere. Soil moisture is thus widely recognized as a key variable in numerous environmental disciplines especially in meteorology, hydrology and agriculture. For hydrological and agricultural purposes, the estimation of soil moisture is crucial since it controls (i) the quantity of water available for the growth of vegetation (Rodriguez-Iturbe, 2000), as well as the recharge of deep aquifers (Hodnett and Bell, 1986); (ii) the saturation of soils which controls the partitioning of rainfall between runoff and infiltration (Merz and Plate, 1997). In

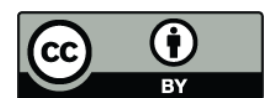

Correspondence to: T. Vischel (theo.vischel@hmg.inpg.fr) meteorology, the soil moisture content has a great impact on the transfer of energy from the surface into the atmosphere since it controls the evapotranspiration fluxes (Entekhabi et al., 1996).

An accurate estimation of soil moisture is difficult to obtain since it is highly variable in both space and time (Western and Blöschl, 1999). The two main sources of soil moisture information come from ground-based and remote sensing estimations. In the field, data can be obtained from gravimetric sampling, this gives the most accurate measurement of the soil water content but is obviously not suitable for automation. Probes (Neutron or Time Domain Reflectometry) can be calibrated to also provide an accurate and possibly automated estimation of soil moisture. Ground observations have helped to document soil moisture patterns at plot to hillslope scales (less than $1 \mathrm{~km}^{2}$ ) in different regions of the world (e.g. Grayson et al., 1997; McNamara et al., 2005; De Lannoy et al., 2006; Hébrard et al., 2006). However, when catchment scales are of interest, one is rapidly confronted with scaling issues (Western and Blöschl, 1999) since ground measurements provide soil moisture estimation limited (i) to small spatial support (from few centimetres for probes, to $1 \mathrm{~m}$ for gravimetric sampling) and (ii) to relatively small areas (extension in the order of a few hectares) since the implementation of a probe network of large extent is subject to obvious logistical and economic constraints.

Remote sensing of soil moisture from satellites is a promising alternative to ground measurements. Microwave frequencies are most often used, both in active (scatterometer or SAR) and passive (radiometer) instruments, to estimate soil moisture (see Wagner et al., 2007 for a detailed review). The advantage of microwave remote sensing is that it provides extended soil moisture estimations, gridded on averaged surface (footprint) from tens of metres to $50 \mathrm{~km}$ resolution, scales more suitable for catchment hydrology. However microwave estimations are only representative of the top few

Published by Copernicus Publications on behalf of the European Geosciences Union. 


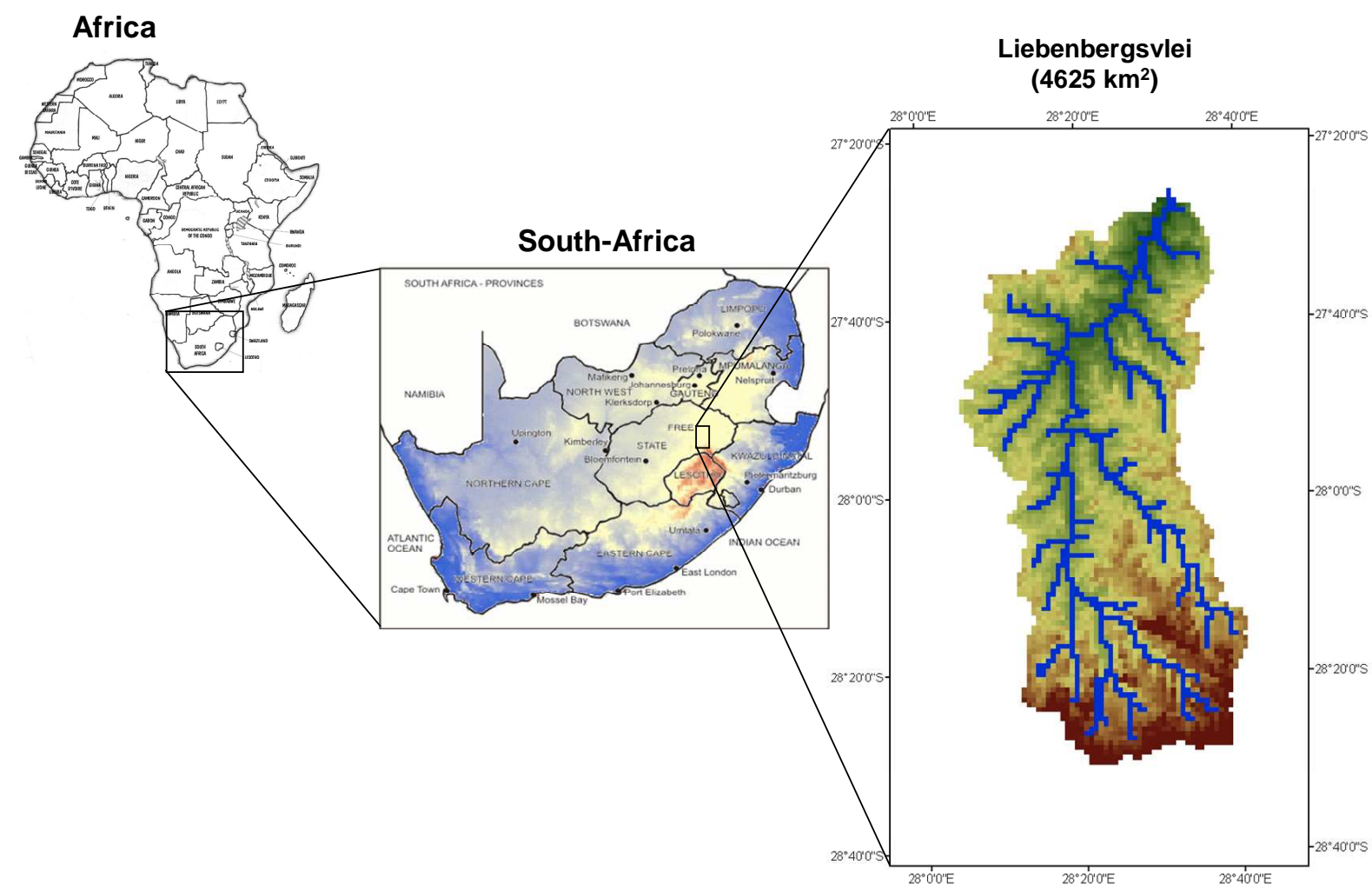

Fig. 1. Location of the Liebenbergsvlei catchment $\left(4625 \mathrm{~km}^{2}\right)$, South Africa.

centimeters of soil, provided that the vegetation is not too dense, and the data availability is often dependent on a low frequency repeat cycle at a point (from 1 day to several weeks depending on the satellite).

Due to the uncertainties associated with the estimation of soil moisture, Kostov and Jackson (1993) suggest that the ideal approach for estimating soil moisture is to combine soil moisture measurements with hydrological models by using assimilation techniques. In fact, remotely sensed soil moisture is often directly assimilated into hydrological models (Ottlé and Vidal-Madjar, 1994; Pauwels et al., 2002; Parajka et al., 2006) or into land surface schemes (Bruckler and Witono, 1989; Houser et al., 1998; Reichle et al., 2001; Walker et al., 2001) in order to initialize, drive, update and/or re-calibrate models, with the main objective of improving the simulations of river discharges or atmospheric fluxes respectively. However, very few studies in the literature detail the comparison between the estimations of soil moisture from remote sensing with the estimations from hydrological models (Biftu and Gan, 2001; Parajka et al., 2006). One must however be able to know a priori the compatibility between the model and remotely sensed soil moisture estimations to better evaluate the effective potential of (i) hydrological models to provide back-calculated estimations of soil moisture for evaluating remotely sensed soil moisture, followed by the use of physical disaggregation tools to improve the low res- olution typical of remotely sensed soil moisture fields, (ii) remotely sensed soil moisture estimates to be assimilated into hydrological models. Wagner et al. (2003) point out the necessity of comparing remotely sensed soil moisture with independent data derived from ground observations, models and/or other remote sensing techniques. Blyth (2002) mentions the necessity of modelling the soil moisture in detail and intercomparing models and data. Pellenq et al. (2003) argue that it is essential to accurately understand all the processes involved in the soil moisture variability and their scale interactions. For that purpose, Western et al. (2002) point out the potential of process-based hydrological models that explicitly represent the dynamic and the spatial scales of the processes that control the soil moisture.

In the present study, we compare two independent approaches of soil moisture estimation on a regional size catchment in South Africa (Liebenbergsvlei, $4625 \mathrm{~km}^{2}$ ). The first estimates are derived from the physically-based distributed hydrological model TOPKAPI (Liu and Todini, 2002). The second set of estimates are derived from the scatterometer on board the European Remote Sensing satellite ERS.

The region, data and hydrological model are presented in Sect. 2. In Sect. 3, the capacity of the TOPKAPI model to mimic the discharges on the studied catchment is evaluated. In Sect. 4, the modelled and remotely sensed soil moisture estimates are compared. The results are discussed in Sect. 5. 


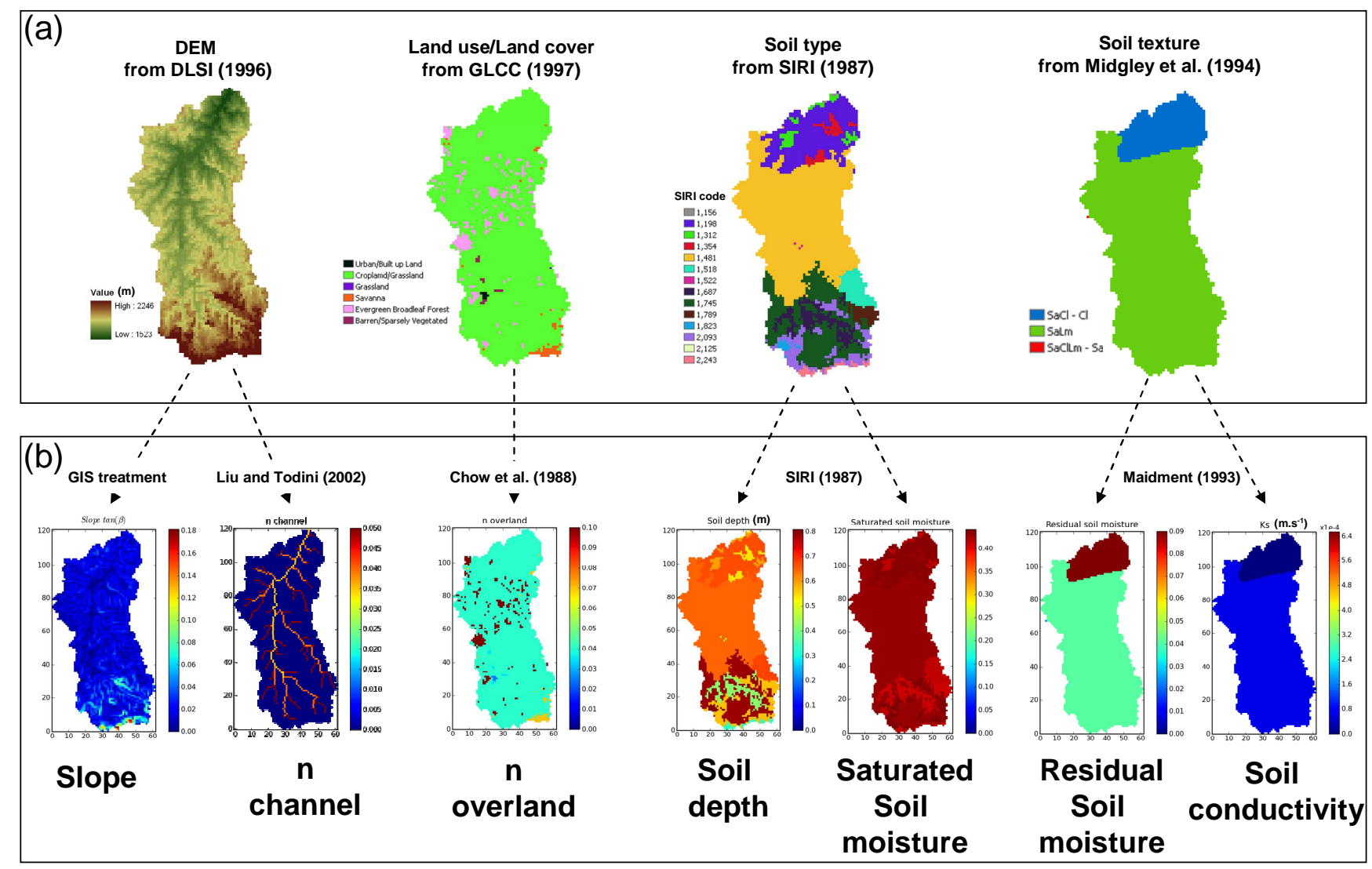

Fig. 2. (a) Catchment characteristics. (b) Estimations a priori of the TOPKAPI model parameters.

\section{Region, data and hydrological model}

\subsection{Characteristics of the Liebenbergsvlei catchment}

The Liebenbergsvlei catchment $\left(4625 \mathrm{~km}^{2}\right)$ is located in the Free State province of South Africa (Fig. 1). The climate is semi-arid, characterized by a mean annual rainfall between 600 and $700 \mathrm{~mm}$ and a mean annual potential evaporation between 1400 and $1500 \mathrm{~mm}$. The landscape is characterized by (i) hillslopes and steep relief in the southern part of the catchment which corresponds to the border of the Lesotho and the Maluti mountains, (ii) grassland and cropland over the bulk of the catchment since farming is the main activity in the region. These features are shown in the two first digital maps of Fig. 2a (Digital Elevation Model-DLSI, 1996; and Landcover/use-GLCC, 1997). Information about soil properties is also available (Fig. 2a, Soil type-SIRI, 1987; Soil texture-Midgley et al., 1994).

\subsection{Hydrologic data set}

\subsubsection{Rainfall and flow data}

Hydrological data are available on the catchment (Fig. 3). A network consisting of 45 tipping bucket rain gauges provided
5 min. time step ground rainfall measurement for the period 1993-2002.

Two flow gauges (CH8020 and CH8026, labelled 1 and 2 in Fig. 3) are available at the outlet of the catchment and further upstream, with uneven data availability and quality between 1993 and 2001. External flows arrive from Lesotho via an inter-basin transfer, beginning in September 1997. These inter-basin transfer flows are recorded at a station located at the outlet of the transfer tunnel (CH8036, labelled 3 in Fig. 3). The quality of the flow data at stations 1 and 2 (in terms of data availability) has improved since 2002, but the recent flow data were not used because the dense rain gauge network was no longer operational after the year 2002.

\subsubsection{Satellite derived soil moisture data}

The remotely sensed soil moisture estimates used in this study are derived from scatterometers on-board of the satellites ERS-1 and ERS-2 (Wagner et al., 2003). The ERS scatterometer is a C-band radar $(5.3 \mathrm{GHz})$ operated at vertical polarization and a spatial resolution of $50 \mathrm{~km}$ at a $25 \mathrm{~km}$ grid spacing. Global coverage is achieved by the satellite every 3 or 4 days on average, but since the ERS scatterometer is in operational conflict with the ERS Synthetic Aperture Radar, only a part of the coverage is effectively available for 


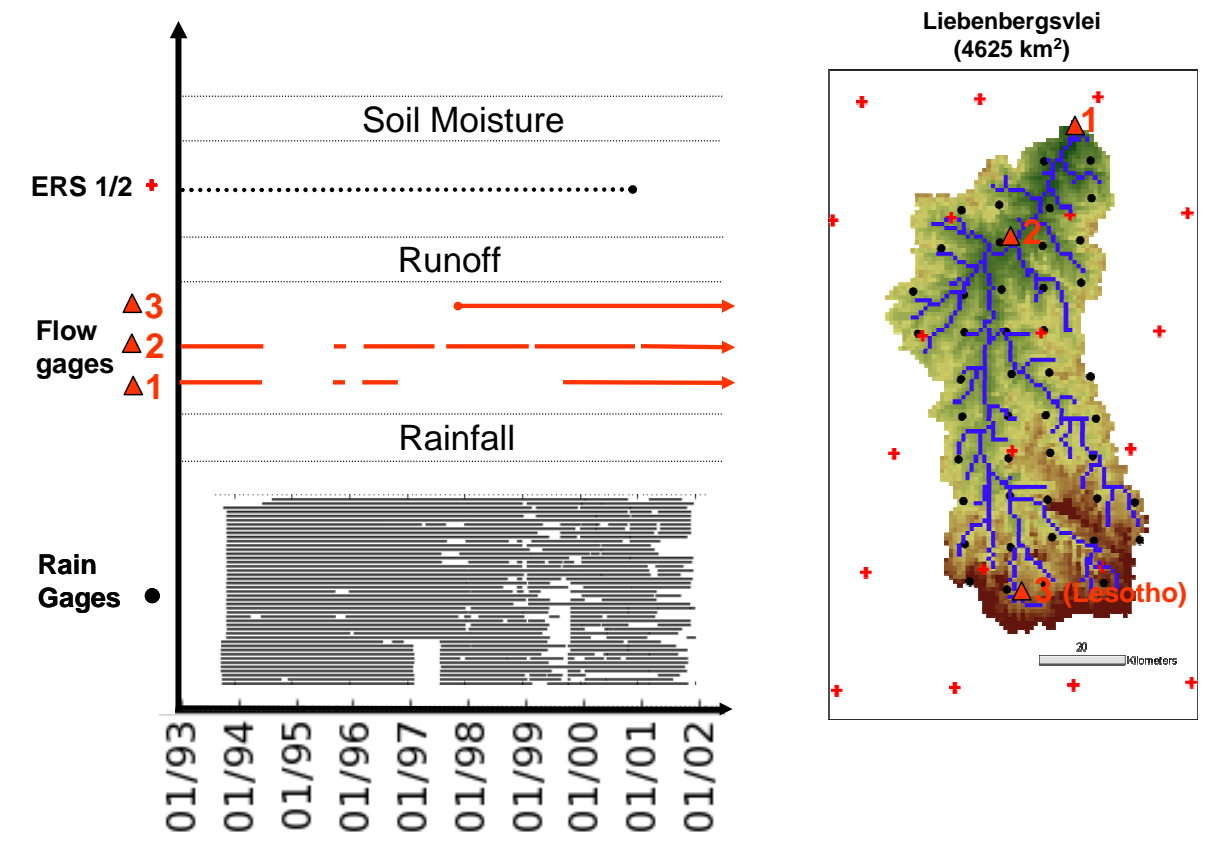

Fig. 3. Hydrological data availability on the Liebenbergsvlei catchment, South Africa.

scatterometer measurements. The repeat cycle at one point is thus 7 days on average, varying irregularly from 3 to 10 days. ERS-1 and ERS-2 have acquired backscatter data since the launch of ERS-1 in 1991 up to the present. However, ERS-2 data availability has been affected by the failures of the gyroscopes in January 2001 and of the tape record in June 2003, for which reason only data for the years 1992 to 2000 have been available for this study.

The scatterometer soil moisture retrieval algorithm takes into account the effects of land cover, surface roughness and seasonal vegetation development on the radar signal. After some regional studies (Wagner et al., 1999a, b, c) the algorithm was successfully applied on a global scale and has resulted in the first global remotely sensed soil moisture data set for the period 1992-2000 (Wagner et al., 2003). The data have been released in 2002 and can be obtained from http://www.ipf.tuwien.ac.at/radar/. The data have been evaluated at local (Pellarin et al., 2006), regional (Crow and Zhan, 2007) and global (Dirmeyer et al., 2004) scale. No study has yet evaluated the quality of the scatterometer soil moisture data at local to regional scales in Africa. The ERS scatterometer grid points over the Liebenbergvlei are represented by the red crosses on Fig. 3.

Scatterometer measurements are sensitive to the moisture content of the surface soil layer due to the strong variation of the dielectric constant of the soil with water content. However other factors influence the scatterometer backscatter signal. Soil moisture retrieval methods must mainly take into account the effects of vegetation, surface roughness and heterogeneous land cover. The retrieval method technique adopted for the data used here is based on the change detection method proposed by Wagner et al. (1999a). To account for effects of roughness and heterogeneous land cover, seasonally varying minimum and maximum backscatter curves $\left(\sigma_{\text {dry }}^{0}\right.$ and $\left.\sigma_{\text {wet }}^{0}\right)$ are determined based on the nine-year measurement period 1992-2000. The two limiting reference values are assumed to be representative of the vegetated land surface under respectively dry and saturated soil conditions. The measured backscatter coefficients are then compared to $\sigma_{\mathrm{dry}}^{0}$ and $\sigma_{\text {wet }}^{0}$, resulting in the definition of topsoil moisture contents $m_{s}(<5 \mathrm{~cm})$ interpreted as a surface soil moisture (i.e. a relative quantity) ranging between 0 and 1 (respectively, $0-100 \%$ ), scaled between zero soil moisture and saturation. At any time $t, m_{s}$ is then defined as:

$m_{s}(t)=\frac{\sigma^{0}(t)-\sigma_{\mathrm{dry}}^{0}}{\sigma_{\mathrm{wet}}^{0}-\sigma_{\mathrm{dry}}^{0}}$

The effects of plant growth and decay are taken into account through the application of varying seasonally $\sigma_{\text {dry }}^{0}$ and $\sigma_{\text {wet }}^{0}$ values as proposed by Wagner et al. (1999b). This method exploits the multi-incidence capabilities of the ERS scatterometer to describe the effect of enhanced volume scattering in the vegetation layer and the corresponding decrease of the ground scattering contribution.

\subsection{The hydrological model TOPKAPI}

TOPKAPI is an acronym which stands for TOPographic Kinematic APproximation and Integration and is a physically-based distributed rainfall-runoff model. In the 
Table 1. Expressions and/or typical values of the coefficient $b_{i}$ and $\alpha$ of Eq. (3) for each component store in a cell.

\begin{tabular}{|c|c|c|}
\hline Reservoir & $b_{i}$ & $\alpha$ \\
\hline Soil & $\begin{array}{l}b_{i}=\frac{C_{s_{i}} X}{X^{2 \alpha}} \text { with } C_{s_{i}}=\frac{L_{i} K_{s_{i}} \tan \left(\beta_{i}\right)}{\left(\theta_{s_{i}}-\theta_{r_{i}}\right)^{\alpha} L_{i}^{\alpha}} \\
\text { where: } \\
-X \text { is the cell horizontal dimension } \\
-L_{i} \text { is the soil depth } \\
-K_{s_{i}} \text { is the saturated hydraulic conductivity } \\
-\tan \left(\beta_{i}\right) \text { is the tangent of the ground slope } \beta_{i} \\
-\theta_{s_{i}} \text { is the saturated soil moisture content } \\
-\theta_{r_{i}} \text { is the residual soil moisture content }\end{array}$ & $\begin{array}{l}\alpha=\alpha_{S} \\
\text { with } \\
2 \leq \alpha_{S} \leq 4 \\
\text { Where } \alpha_{S} \text { is a pore-size distribution parameter } \\
\text { (Brooks and Corey, 1964) }\end{array}$ \\
\hline Overland & $\begin{array}{l}b_{i}=\frac{C_{o_{i}} X}{X^{2 \alpha}} \text { with } C_{o_{i}}=\frac{1}{n_{o_{i}}} \sqrt{\tan \left(\beta_{i}\right)} \\
-n_{o_{i}} \text { is Manning's roughness coefficient } \\
-\tan \left(\beta_{i}\right) \text { is the tangent of the ground slope } \beta_{i}\end{array}$ & $\alpha=\alpha_{o}=\frac{5}{3}$ \\
\hline Channel & $\begin{array}{l}b_{i}=\frac{C_{c_{i}} W_{i}}{\left(X_{c} W_{i}\right)^{\alpha}} \text { with } C_{c_{i}}=\frac{1}{n_{c_{i}}} \sqrt{\tan \left(\beta_{c_{i}}\right)} \\
-X_{c} \text { is the channel length }\left(X_{c}=X \text { or } X_{c}=\sqrt{2} X\right) \\
-W_{i} \text { is the width of the channel } \\
-n_{c_{i}} \text { is Manning's roughness coefficient } \\
-\tan \left(\beta_{c_{i}}\right) \text { is the tangent of the channel slope } \beta_{c_{i}}\end{array}$ & $\alpha=\alpha_{c}=\frac{5}{3}$ \\
\hline
\end{tabular}

original version proposed by Liu and Todini (2002), TOPKAPI consists of five main modules comprising soil, overland, channel, evapotranspiration and snow modules. The first three are modules in the form of non-linear reservoirs controlling the horizontal flows. The reservoir equations are approximated by the kinematic wave model differential equations at a point. The well-known point-scale differential equations are then analytically integrated in space to the finite dimension of a grid cell, which is taken to be a pixel of the digital elevation model (DEM) that describes the topography of the catchment. The evapotranspiration module implemented for this study has been slightly modified compared to the original module presented in Liu and Todini (2002). The snow module component is ignored in the present study as the influence of snow can be neglected for the Liebenbergsvlei catchment.

\subsubsection{Model assumptions}

The TOPKAPI model is based on six fundamental assumptions (Liu and Todini, 2002):

1. Precipitation is constant in space and time over the integration domain (namely the single grid cell or pixel and the basic time interval, usually few hours).

2. All precipitation falling on the soil infiltrates, unless the soil is already saturated (Dunne, 1978).

3. The slope of the groundwater table coincides with the slope of the ground.
4. Local transmissivity, like horizontal subsurface flow in a cell, depends on the integral of the total water content of the soil in the vertical.

5. In the soil surface layer, the saturated hydraulic conductivity is constant with depth and, due to macro-porosity, is much larger than in deeper layers.

6. During the transition phase, the variation of water content in time is constant in space.

The absence in the TOPKAPI model of an explicit representation of infiltration-excess runoff processes (Hortonian processes) might be of concern for a semi-arid catchment like the Liebenbergsvlei. However, as discussed later (see Sect. 5) recent field experiments have shown that such an assumption is in fact realistic on the Liebenbergsvlei.

\subsubsection{Ordinary Differential Equations controlling the reser-} voir flows

The equations of each of the three reservoirs (soil, overland and channel) that comprise a cell $i$ can be written as a classical differential equation of continuity:

$\frac{d V_{i}}{d t}=Q_{i}^{\text {in }}-Q_{i}^{\text {out }}$

where all the variables are observed at time $t: V_{i}$ is the total volume stored in the reservoir, $\frac{d V_{i}}{d t}$ is the rate of change of water storage, $Q_{i}^{\text {in }}$ is the total inflow rate to the reservoir, $Q_{i}^{\text {out }}$ is the total outflow rate from the reservoir. 
Table 2. Variables computed at each cell $i$ between time $t$ and $\Delta t$ : see Fig. 4 for flow paths.

\begin{tabular}{|c|c|c|c|c|c|}
\hline & $\begin{array}{l}\text { Initial value: } \\
\text { Volume at } t\end{array}$ & $\begin{array}{l}\text { Inflow rates during } \\
{[t, t+\Delta t]}\end{array}$ & $\begin{array}{l}\text { ODE solution: } \\
\text { Volume at } t+\Delta t\end{array}$ & $\begin{array}{l}\text { Outflow rates during } \\
{[t, t+\Delta t]}\end{array}$ & $\begin{array}{l}\text { Flow partitioning: } \\
\text { Flow rate to next cell during } \\
{[t, t+\Delta t]}\end{array}$ \\
\hline Soil & $V_{s_{i}}(t)$ & $Q_{s_{i}}^{\text {in }}=P_{i} X^{2}+Q_{s_{i}}^{\text {up }}+Q_{o_{i}}^{\text {up }}$ & $V_{S_{i}}(t+\Delta t)$ & $\begin{array}{l}Q_{s_{i}}^{\text {out }} \\
=Q_{s_{i}}^{\text {in }}-\frac{V_{s_{i}}(t+\Delta t)-V_{s_{i}}(t)}{\Delta t}\end{array}$ & $\begin{array}{l}\text { To next soil reservoir } \\
Q_{s_{i}}^{\text {out }}-Q_{s_{i}}^{\text {excess }}-\frac{W_{i} X_{c}}{X^{2}} Q_{s_{i}}^{\text {out }}\end{array}$ \\
\hline Overland & $V_{o_{i}}(t)$ & $\begin{array}{l}Q_{o_{i}}^{\text {in }}=Q_{s_{i}}^{\text {excess }} \\
=\max \left(0, Q_{s_{i}}^{\text {out }}-Q_{s} \max _{i}\right) \\
\text { with } Q_{s} \max _{i}=X K_{s_{i}} L_{i} \tan (\beta)\end{array}$ & $V_{o_{i}}(t+\Delta t)$ & $\begin{array}{l}Q_{o_{i}}^{\text {out }} \\
=Q_{o_{i}}^{\text {in }}-\frac{V_{o_{i}}(t+\Delta t)-V_{o_{i}}(t)}{\Delta t}\end{array}$ & $\begin{array}{l}\text { To next soil reservoir } \\
Q_{o_{i}}^{\text {out }}-\frac{W_{i} X_{c}}{X^{2}} Q_{o_{i}}^{\text {out }}\end{array}$ \\
\hline Channel & $V_{c_{i}}(t)$ & $Q_{c_{i}}^{\text {in }}=Q_{c_{i}}^{\text {up }}+\frac{W_{i} X_{c}}{X^{2}} Q_{s_{i}}^{\text {out }}+\frac{W_{i} X_{c}}{X^{2}} Q_{o_{i}}^{\text {out }}$ & $V_{c_{i}}(t+\Delta t)$ & $\begin{array}{l}Q_{c_{i}}^{\text {out }} \\
=Q_{c_{i}}^{\text {in }}-\frac{V_{c_{i}}(t+\Delta t)-V_{c_{i}}(t)}{\Delta t}\end{array}$ & $\begin{array}{l}\text { To next channel } \\
Q_{c_{i}}^{\text {out }}\end{array}$ \\
\hline
\end{tabular}

The kinematic wave approach used to resolve the continuity and mass balance in TOPKAPI (by neglecting the dynamic acceleration terms in the energy equation) leads to a nonlinear relationship between $Q_{i}^{\text {out }}$ and $V_{i}$, turning Eq. (2) into to an ordinary nonlinear differential equation (ODE) of the form:

$\frac{d V_{i}}{d t}=Q_{i}^{\text {in }}-b_{i} V_{i}^{\alpha}$

where $b_{i}$ is constant in time (it frequently varies spatially) and is a function of the geometrical and physical characteristics of the reservoir. The parameter $b_{i}$ also depends on the exponent coefficient $\alpha$ which originates from either the infiltration equations describing soil reservoir behaviour, or from Manning's equations used in the overland and channel reservoir specifications (see Liu and Todini, 2002 for more details about the theoretical basis). For the three reservoirs (soil, overland and channel), the expressions of $b_{i}$ and $\alpha$ are reported in Table 1. Depending on the type of reservoir, $Q_{i}^{\text {in }}$ is a combination of the forcing variables (interconnecting flows between the elemental storage reservoirs within the cell and from upper connected cells, also including rainfall and evapotranspiration in the case of the soil reservoir; Table 2).

At each simulation time step, the inflow rate $Q_{i}^{\text {in }}$ is computed, assumed to be a constant over the interval, then the ODE equation is solved by numerical integration. In this application of TOPKAPI a combination of a quasi-analytical solution (proposed by Liu and Todini, 2002) with a numerical integration procedure based on the Runge-Kutta-Fehlberg method (see e.g. Gerald and Wheatley, 1992) was used. This fast, numerically stable and accurate hybrid scheme was used to integrate the appropriate variations of Eq. (3) over the time interval $\Delta t$, dependent on the initial volume stored in the reservoir at time $t$, to obtain the volume $V_{i}(t+\Delta t)$ stored at $t+\Delta t$. This solution of Eq. (3) differs from the method recommended by Liu and Todini (2002) and was chosen after carefully examining the ability of the various solutions to numerically satisfy the continuity equations at each time step and in each cell. In Table 2 all the variables that are com- puted for each reservoir from the ODE finite difference solution showing the reservoir and cell connectivity are reported. Table 2 is associated with Fig. 4 which illustrates the fluxes and connections for a typical modelled cell. Liu and Todini (2002) declare that the flow direction drainage in TOPKAPI is only possible in four directions (north, east, south or west). However the limitation of the drainage to 4 directions can lead to an unrealistic representation of the relief variability. Indeed, the filling of the sinks in the Digital Elevation Model treatment results in a strong smoothing of the relief variability because of the limitation of the drainage in only 4 directions (D4). For this reason, the TOPKAPI model was adapted to be compatible with 8 direction drainage (D8), which includes the 4 extra pixels beyond the diagonals. This was achieved by using a calculation procedure (separate from the GIS based one) to obtain the slopes of the soil and overland reservoirs as distinguished from the slopes of the channel, each using D8. The slopes of the soil and overland reservoirs were computed according to a neighbourhood function more representative of the mean slope within the cell and thus more representative of the transfers inside the cell (in and over the soil). The slopes used to transfer the flows in the channel drainage network were computed from cell to cell in a down-stream direction using differences in altitude.

\subsubsection{Evapotranspiration}

The evapotranspiration module was slightly modified from the original version of Liu and Todini (2002). In the channel, the evaporation is extracted at the rate of the potential evaporation of a free surface of water. On the hillslopes, the actual evapotranspiration is computed as a proportional ratio of the reference crop evapotranspiration depending on a constant crop factor $k_{c}$ and the current saturation of the reservoir computed at each time step. 


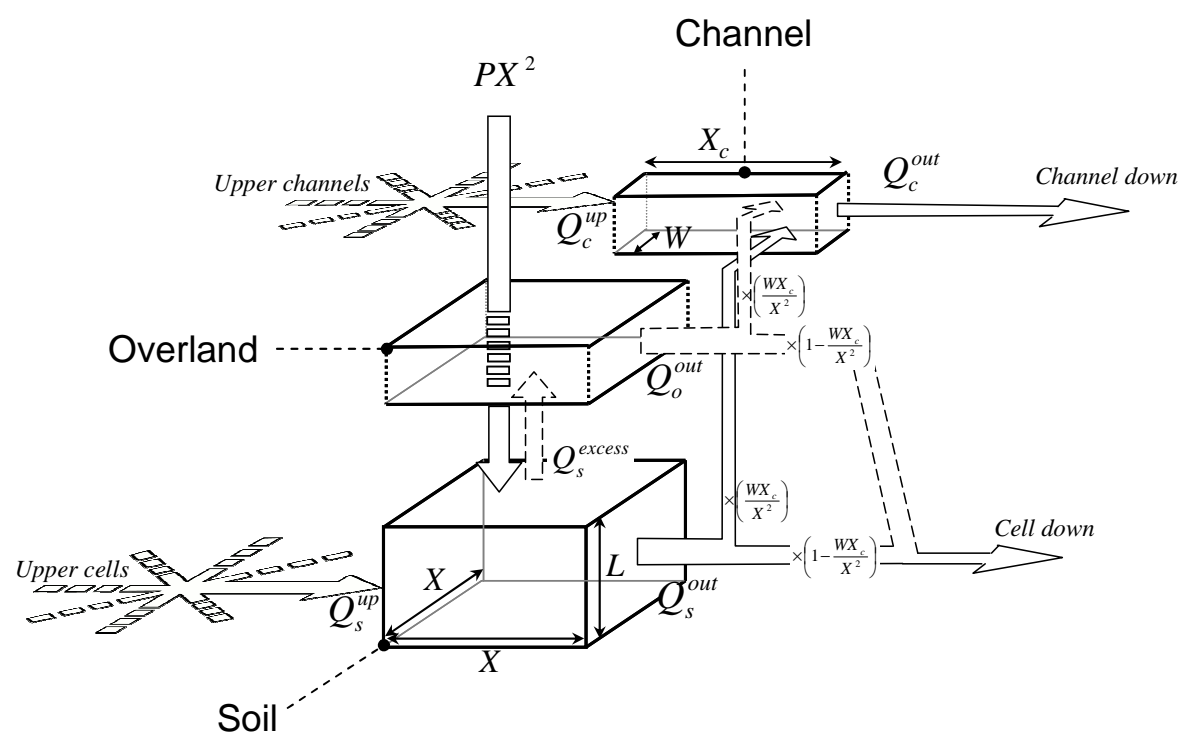

Fig. 4. Water balance in the TOPKAPI model (note that for clarity, the evapotranspiration losses are not represented on the figure).

\section{Comparison between modelled and observed discharges}

\subsection{Modelling features}

\subsubsection{Selected period}

From the data set presented in Sect. 2.2, two seasons of eight months were selected during which the rainfall and flow data were both continuous and of good quality. The first season (Season 1) between November 1993 and June 1994 was used to adjust the parameters of the TOPKAPI model, with more emphasis on the flows at station 2, because the flows were more trustworthy. It is worth noting here that the measurement error of station 2 is estimated at less than $5 \%$ by the South African Department of Water Affairs and Forestry (Brink Du Plessis, 2007, personal communication). The second season (Season 2) between November 1999 and June 2000 is used in Sect. 3.2 as a model verification period. In both seasons the modelled soil moisture is compared with the corresponding remotely sensed soil moisture in Sect. 4.

\subsubsection{Model resolution}

The model spatial resolution was imposed by the desire to use a freely available DEM at $1 \mathrm{~km}$ (DLSI, 1996; see Sect. 2.1). A $6 \mathrm{~h}$ time step was chosen which is small enough to model the main discharge variations, since the catchment response time is estimated to be between 1 and 2 days.

\subsubsection{Forcing variables}

For the two seasons considered in this study, the $6 \mathrm{~h}$ time step rainfields were Kriged at $1 \mathrm{~km}$ resolution by using a climato- logical spherical variogram with range of $30 \mathrm{~km}$ and a zero nugget (guided by Wesson and Pegram, 2006).

As no evapotranspiration data are available for the simulated periods on the catchment, the mean annual evapotranspiration over the region was used and disaggregated at a daily time step, according to a mean seasonal signal determined by McKenzie and Craig (1999).

\subsection{TOPKAPI parameter adjustment}

\subsubsection{A priori estimation of the parameters}

Because of its physical basis, the model parameters can be estimated a priori from the catchment characteristics (Liu and Todini, 2002). The a priori values or range of values of the parameters of the model is reported in Table 3, as well as the data and/or literature references that were used to infer the values. Among the 14 parameters of the TOPKAPI model, 7 are spatially variable. As a complement to Table 3 , Fig. 2b shows the maps of the spatially variable parameters and their link to the data available over the Liebenbergsvlei catchment (Fig. 2a). A Geographical Information System was used in junction with the DEM in order to (i) compute the slope (ground slope $\tan (\beta)$ and channel slope $\tan \left(\beta_{c}\right)$ ) of each cell (ii) delineate the stream network and (iii) compute the Strahler orders of each channel reach (Strahler, 1957). The ordering method of Strahler is used to infer the values of the channel roughness Manning's coefficients $n_{c}$. In Liu and Todini (2002), channel orders of 1, 2, 3 and 4 were assigned values of $0.045,0.04,0.035$ and 0.035 for the Upper Reno catchment in Italy. In the absence of any information about the channel reach properties, these values were assumed to be suitable as starting values for the Liebenbergsvlei catchment. 
Table 3. Values of the TOPKAPI model parameters estimated a priori from data and literature, and values of multiplying factors used for the calibration procedure.

\begin{tabular}{|c|c|c|c|c|}
\hline Parameter & & Value a priori & Origin and references & Calibrated multiplying factor value \\
\hline \multicolumn{5}{|l|}{ Spatially variable (cf. Fig. 2b) } \\
\hline Ground Slope & $\tan \beta$ & $1.7 \mathrm{E}-4-1.81 \mathrm{E}-1$ & DEM (DLSI,1996) & \\
\hline Channel Slope & $\tan \beta_{c}$ & $4.0 \mathrm{E}-5-3.1 \mathrm{E}-1$ & DEM (DLSI,1996) & \\
\hline Depth of surface soil layer (m) & $L$ & $0.33-0.81$ & Soil type map (SIRI,1987) & $\operatorname{fac}_{L}$ \\
\hline Saturated hydraulic conductivity $\left(\mathrm{m} \mathrm{s}^{-1}\right)$ & $K_{s}$ & $1.67 \mathrm{E}-6-5.18 \mathrm{E}-4$ & $\begin{array}{l}\text { Soil texture map (Midgley et al., 1994) } \\
\text { + Maidment (1993) }\end{array}$ & $\operatorname{fac}_{K_{s}}$ \\
\hline Residual soil moisture content & $\theta_{r}$ & $0.02-0.09$ & $\begin{array}{l}\text { Soil texture map (Midgley et al., 1994) } \\
\text { + Maidment (1993) }\end{array}$ & \\
\hline Saturated soil moisture content & $\theta_{s}$ & $0.41-0.44$ & Soil type map (SIRI,1987) & \\
\hline Manning's surface roughness coeff. & $n_{o}$ & $0.025-0.1$ & $\begin{array}{l}\text { Landuse map (GLCC, 1997) } \\
+ \text { Chow et al. (1988) }\end{array}$ & $\mathrm{fac}_{n_{o}}$ \\
\hline Manning's channel roughness coeff. & $n_{c}$ & $0.035-0.045$ & Strahler order method (Liu and Todini 2002) & $\mathrm{fac}_{n_{c}}$ \\
\hline \multicolumn{5}{|l|}{ Constant } \\
\hline Horizontal dimension of cell (m) & $X$ & 1000 & DEM (DLSI,1996) & \\
\hline Non-linear soil exponent & $\alpha_{s}$ & 2.5 & Liu and Todini (2002) & \\
\hline Max. channel width at outlet (m) & $W_{\max }$ & 40 & Field pictures & \\
\hline Min. channel width for $A_{\text {threshold }}(\mathrm{m})$ & $W_{\min }$ & 5 & - & \\
\hline Area required to initiate channel $\left(\mathrm{m}^{2}\right)$ & $A_{\text {threshold }}$ & 2500000 & - & \\
\hline Crop factor & $k_{c}$ & 1. & Landuse map (GLCC, 1997) & \\
\hline
\end{tabular}

The values of the overland roughness Manning's coefficient $n_{o}$ were derived from the landuse/cover map (GLCC, 1997), using the tables in Chow et al. (1988). Maps of soil depths $L$ and saturated soil moisture $\theta_{s}$ were already available over the catchment in the data set of soil properties (SIRI, 1987). The residual soil moisture $\theta_{r}$ and the hydraulic conductivity at saturation $K_{S}$ were derived from the soil texture map (Midgley et al., 1994) according to parameter tables for the Green-Ampt infiltration model (Maidment, 1993). As in Liu and Todini (2002), the pore-size distribution parameter $\alpha_{s}$ was uniformly set to the value 2.5 . A sensitivity analysis (not presented here) showed that varying the value of $\alpha_{s}$ in the realistic range of its values (between 2 and 4 according to Liu and Todini, 2002) had only a small influence on the simulations. As a first approximation, and because of the relatively homogeneous cropland/grassland landcover, the crop factor $k_{c}$ was assumed to be spatially uniform over the catchment and equal to 1 .

The other parameters concern the channel geometry. The threshold value of the area over which the water is considered to be drained in a channel ( $\left.A_{\text {threshold }}\right)$ was fixed at $25 \mathrm{~km}^{2}$ after checking the limit of the streams with those shown on 1:250000 maps. The minimum and maximum width of the channel (respectively $W_{\min }$ and $W_{\max }$ ) were fixed at respectively $5 \mathrm{~m}$ and $35 \mathrm{~m}$ (estimated from photographs taken at the flow stations). A linear relationship between the drained area and the channel width at a point proposed by Liu and Todini (2002) was used to determine the channel width along the catchment.
Because of the uncertainty in the estimation of the catchment's characteristics from a priori datasets, a calibration was required.

\subsubsection{Calibration procedure}

The method used to calibrate the model was inspired by the Ordered Physics-based Parameter Adjustment method (OPPA) proposed by Vieux et al. (2004). This method aims to calibrate the physically distributed hydrological model parameters in a specific order. First the parameters controlling the production of the runoff are adjusted such that a discharge volume objective function is minimized. Then the parameters controlling the runoff routing are adjusted such that a discharge timing objective function is minimized. According to a sensitivity analysis of the model parameters (not shown here, but also in accordance with the work of Liu et al., 2005), the most important parameters controlling the production in TOPKAPI are the soil depth $L$ and the soil conductivity $K_{s}$, while the timing of runoff is mainly controlled by the Manning roughness of the channel $n_{c}$ and of the overland surface $n_{o}$. In the absence of any quantitative information, the initial soil moisture $V_{s \text { _initial, which was shown }}$ to have a strong influence on the simulations, was also calibrated. Ten values of mean catchment saturation between $1 \%$ and $90 \%$ were tested.

In order to have realistic patterns of initial soil moisture fields that preserve the most likely spatial distribution of soil moisture on the catchment, the model was run with the a priori parameters and zero rainfall input, but with the initial soil 


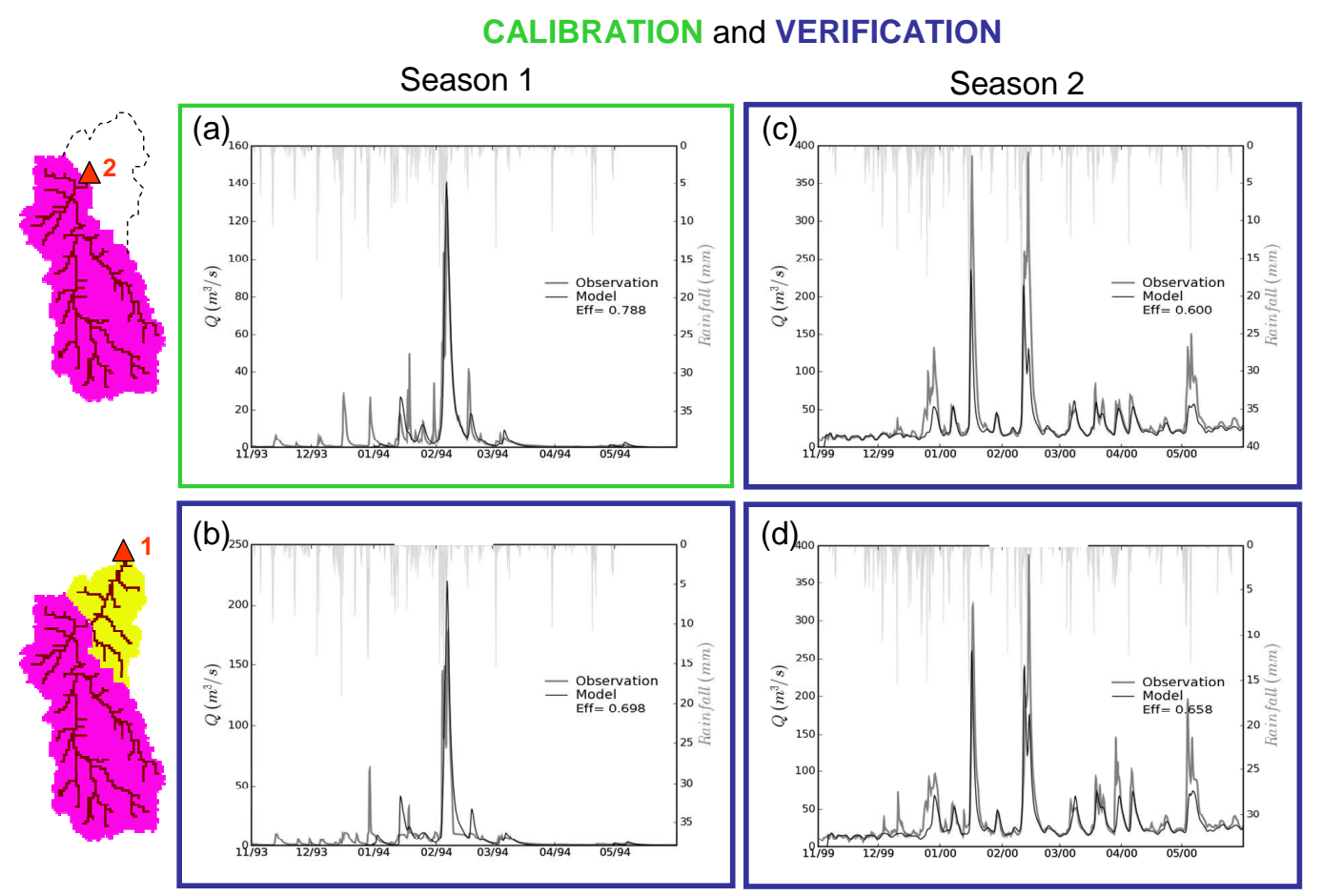

Fig. 5. Modelled and observed hydrographs. Calibration (a) and verification (b, c, d) of the model at two stations and for two distinct 8 month seasons.

saturation of the catchment set at $100 \%$ (meaning that each cell was $100 \%$ saturated). During the process of drainage with zero input, at each 6 hourly simulation time step, the mean catchment saturation was calculated. From these simulations, 10 soil moisture maps were extracted as the cells drained, corresponding as closely as possible to mean saturation levels between $90 \%$ and $1 \%$. These 10 residual moisture maps were used as reference soil moisture maps for the various levels of initialisation.

As suggested by Vieux et al. (2004) and by most of the studies dealing with the calibration of distributed hydrological models, the parameters are not tuned independently for each cell, but the parameter map is calibrated by using a multiplicative factor applied uniformly in space. For our application the four multiplicative factors to be applied were fac ${ }_{L}$ (for the soil depth), $\mathrm{fac}_{K_{s}}$ (for the hydraulic conductivity), fac $_{n_{o}}$ (for the overland roughness) and fac $n_{n_{c}}$ (for the channel roughness).

The trio of parameters $\left(\mathrm{fac}_{L}, \mathrm{fac}_{K_{s}}, V_{S_{\perp} \text { initial }}\right)$ and the pair of parameters ( $\mathrm{fac}_{n_{o}}, \mathrm{fac}_{n_{c}}$ ) were calibrated independently, after verifying that they were effectively independent, meaning that their variation influenced exclusively (respectively) the production and the timing of runoff. The triplet ( $\mathrm{fac}_{L}$, $\mathrm{fac}_{K_{s}}, V_{S_{-} \text {initial }}$ ) was adjusted in order to minimize the Root Mean Square Error (RMSE) objective function comparing modelled and observed discharge volumes aggregated at a monthly time step. Then the pair $\left(\mathrm{fac}_{n_{o}}, \mathrm{fac}_{n_{c}}\right)$ was adjusted using the regression coefficient $\left(R^{2}\right)$ in order to match the timing of observed and modelled discharges at a $6 \mathrm{~h}$ time step.

In order to reduce the computation time required by the calibration procedure, the calibration was carried out using the flows estimated at station 2 (see Fig. 3). At this station, the drainage area is $3563 \mathrm{~km}^{2}$, which effectively preserves the main soil heterogeneity of the entire catchment.

\subsection{Results}

Figure 5a shows the results of the calibration. There is a good correspondence between observed and modelled hydrographs (Nash efficiency of 0.788). In Table 3 the values of the four calibrated multiplying factors are reported. It is worth noting that all the values of the parameters estimated a priori were quite appropriate except for the channel roughness and the soil conductivity which have been increased respectively by a factor of 1.7 and 60; this aspect will be discussed in Sect. 5. The initial soil moisture was also adjusted by calibration, using the 10 sets of initial conditions, to a mean value of $40 \%$ over the catchment.

As a verification of the relevance of the calibration procedure and its effect on other discharge time series, the calibrated model was applied to the entire catchment. For the same season (Season 1) the observed and modelled discharges at the outlet of the catchment (Station 1) are plotted in Fig. 5b. Globally, there is once again a good 
correspondence between observed and modelled flows, however at some points, the observed data seem to be unreliable since some peaks recorded at Station 2 do not appear as they should at the outlet and the recession shape of the main peak discharge seems somewhat unrealistic. In order to check the verification procedure on more reliable data, the model was then applied to an independent season (Season 2). During this season, the discharges are influenced by the inter-basin transfer flows arriving from Lesotho. In order to reliably compare the modelled and observed discharges, the external flows observed at Station 3 were injected at the pixel in the channel located the closest to Station 3. Again in the absence of any information about the initial soil moisture, the value of $40 \%$ calibrated for Season 1 using station 2 was assumed to be applicable for Season 2. Results are plotted in Fig. 5c and d. Again, acceptable simulations of the hydrographs were obtained even if the main peak discharges are unexpectedly underestimated. One can however note that the timing of the flows is remarkably good, especially at the beginning of the season, when in the absence of rainfall, the flows are mainly explained by the external flows that are routed from the upper part of the catchment; these appear pulsed because of hydropower generation. The modelling of the discharges was judged to be done well enough to reliably compare the modelled soil moisture to the remotely sensed data.

\section{Comparison of remotely sensed and modelled soil moisture}

4.1 Definition of a remotely sensed and modelled Soil Water Index (SWI)

As already noted in Sect. 2.2, the remotely sensed soil moisture estimation is representative of the relative water content of the first $5 \mathrm{~cm}$ of topsoil effectively "seen" by the scatterometer. However, for the purpose of the present study, which is to compare the soil moisture as modelled by TOPKAPI and the remotely sensed soil moisture, the variable of concern is the soil moisture in the entire soil layer.

In order to provide a reliable comparison, the soil moisture in the whole soil layer must thus be obtained from the surface soil moisture estimated by the satellite. In addition to the surface soil moisture available in the global ERS soil moisture product, a Soil Water Index (SWI) is provided that aims to estimate the soil moisture profile in the soil horizon from the ERS product. The method used here to estimate SWI was proposed by Wagner et al. (1999c). It is a simple conceptual infiltration model based on an exponential filter, temporally smoothing the signal of the (instantaneously estimated) relative surface soil moisture to give the Soil Water Index, SWI:

$\operatorname{SWI}(t)=\frac{\sum_{i} m_{S}(t) e^{-\left(t-t_{i}\right) / T}}{\sum_{i} e^{-\left(t-t_{i}\right) / T}}$ for $\quad t_{i} \leq t$ where $m_{s}$ is the surface soil moisture estimate from the ERS scatterometer defined in Eq. (1). $T$ represents a characteristic time length depending to the soil properties (mainly soil depth, diffusivity and moisture state). To maintain the crucial independence of the physically based approach of TOPKAPI and the remotely sensed soil moisture estimates, it was decided not to refine the estimation of the parameter $T$ for the particular study area by using the soil data. Thus the value of $T=20$ days, suggested by Wagner et al. (1999c) as an average value, was retained. More detailed discussions of the SWI method can be found in Ceballos et al. (2005) and Pellarin et al. (2006).

A surrogate for SWI can easily be defined for TOPKAPI by computing the relative soil saturation at each catchment cell, for each time step of the simulation.

Two different scales are considered to make the comparison between the modelled and remotely sensed soil moisture. The first is the catchment scale, at this scale: (i) the mean catchment SWI is computed from the hydrological model by averaging over the catchment the SWI computed at each cell, (ii) the mean catchment SWI is computed from the scatterometer data, by averaging over the catchment the SWI computed for the scatterometer grid points in and surrounding the catchment (the average being weighted according to Thiessen polygons). The second scale is the scatterometer footprint scale, which is smaller than the catchment scale. This corresponds to the original scatterometer resolution defined by a circle of diameter $50 \mathrm{~km}$. The footprint SWI is computed from the hydrological model by averaging the SWI computed at each cell within the footprint. In order to make a robust comparison, only the three footprints showing the largest areal coverage of the catchment were considered.

\subsection{Results}

\subsubsection{At catchment scale}

The modelled and remotely sensed mean catchment SWI are compared in Fig. 6 for the two modelled seasons, at the time step of ten days imposed by the ERS sampling interval. There is a very good correspondence between the two SWI estimates, as illustrated by the regression coefficients $\left(R^{2}\right)$ of 0.759 for the first season and 0.923 for the second season. According to the regression equation, a relative bias is observed (which seems to be independent of the season) that is likely to be due to the uncertainties associated with each of the two approaches whose comparison will be discussed in Sect. 5. Despite this, the order of magnitude of the remotely sensed and the modelled SWI is still very similar. As an interesting example, the value of the initial soil moisture, which was calibrated at $40 \%$ for the catchment model, could have been estimated by using the remotely sensed value. This result is very encouraging since the initialization of hydrological models after a dormant period remains a constant problem in hydrology. 


\section{At catchment scale}

Season 1
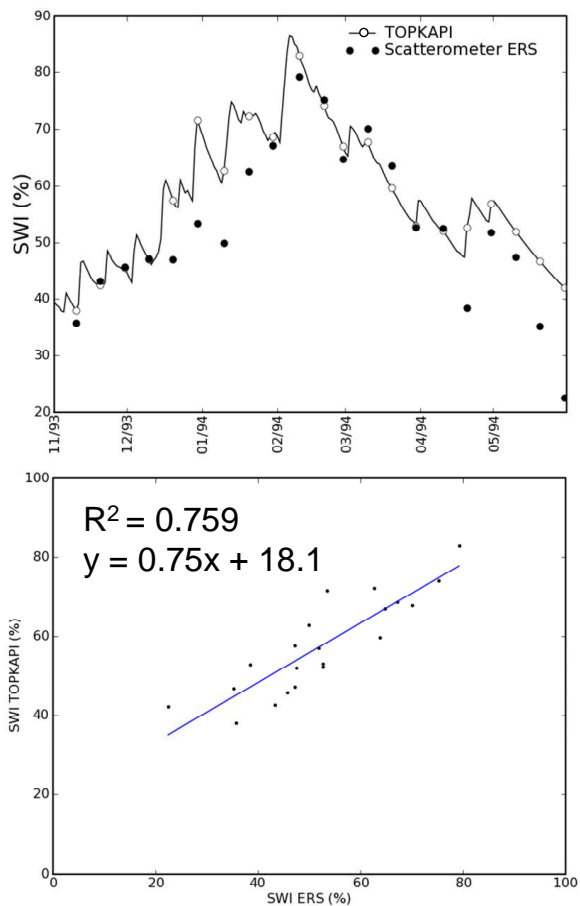

Season 2
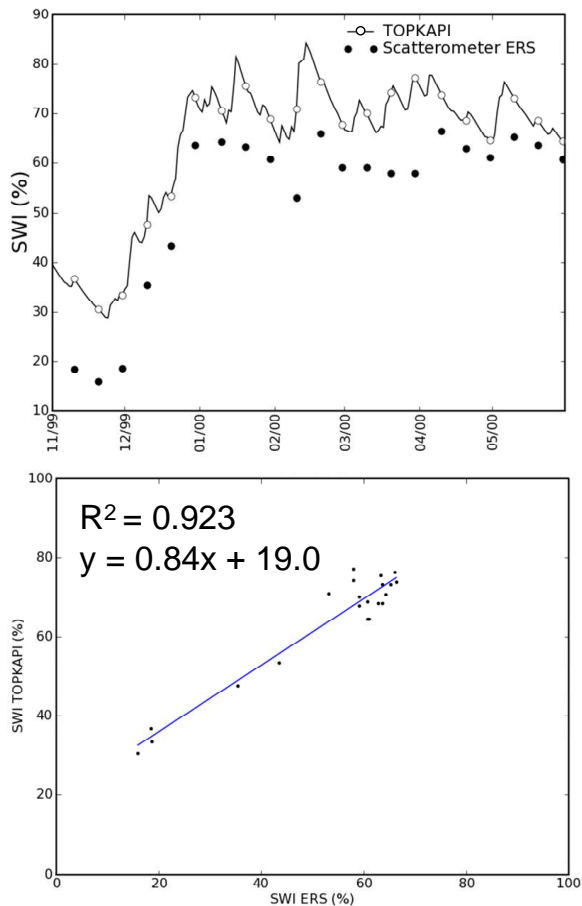

Fig. 6. Comparison between the modelled and the remotely sensed SWI computed at catchment scale. The open circles are the TOPKAPI estimates at time corresponding to the scatterometer estimates (filled circles).

\subsubsection{At footprint scale}

Figures 7 and 8 show respectively the remotely sensed and the modelled SWI at footprint scale and the associated scatter plots. The results show that the good correspondence already found at catchment scale is retained at the smaller scale of the footprint. The correlations are still fair (greater than 0.68), while according to the regression equations, the bias between the two independent SWI estimates is relatively stable and appears to be independent of season and location.

\section{Discussion and conclusion}

\subsection{Summary}

The paper aimed to compare, for the purpose of corroboration, not validation, two independent approaches used to estimate soil moisture at the scale of a region-sized catchment (Liebenbergsvlei, $4625 \mathrm{~km}^{2}$, South Africa). The first estimation was derived from physically based hydrological modelling of the catchment using the TOPKAPI model (Liu and Todini, 2002) and the second was derived from the remotely sensed observations of the scatterometer on board the ERS satellite. A calibration procedure of the TOPKAPI model has been carried out consisting of the adjustment of the four most sensitive parameters of the model according to runoff production and routing. A good agreement was found between observed and modelled hydrographs of the Liebenbergsvlei catchment for both the calibration and the verification period. The comparison between the modelled and the remotely sensed soil moisture estimates was done using the computation of the Soil Water Index ( SWI) which is the relative soil moisture throughout the soil depth. As the satellite only provides soil moisture for the topsoil layer (first $5 \mathrm{~cm}$ ), a conceptual infiltration model developed by Wagner et al. (1999c) was applied to the remotely sensed surface soil moisture estimates in order to estimate an SWI. The comparison between the modelled and remotely sensed SWI was shown to be good with regression coefficient varying between 0.678 and 0.923 . Even if a constant bias of around $19 \%$ is identified, the dynamic of the soil moisture behaviour is very coherent between the two approaches.

\subsection{Discussion}

5.2.1 Comments on the bias between the modelled and remotely sensed soil moisture

As there is no possibility of obtaining the "true" value of soil moisture at catchment scale, it is difficult to precisely assess the reasons for the bias identified between the modelled and remotely sensed soil moisture. It is clear however that the 


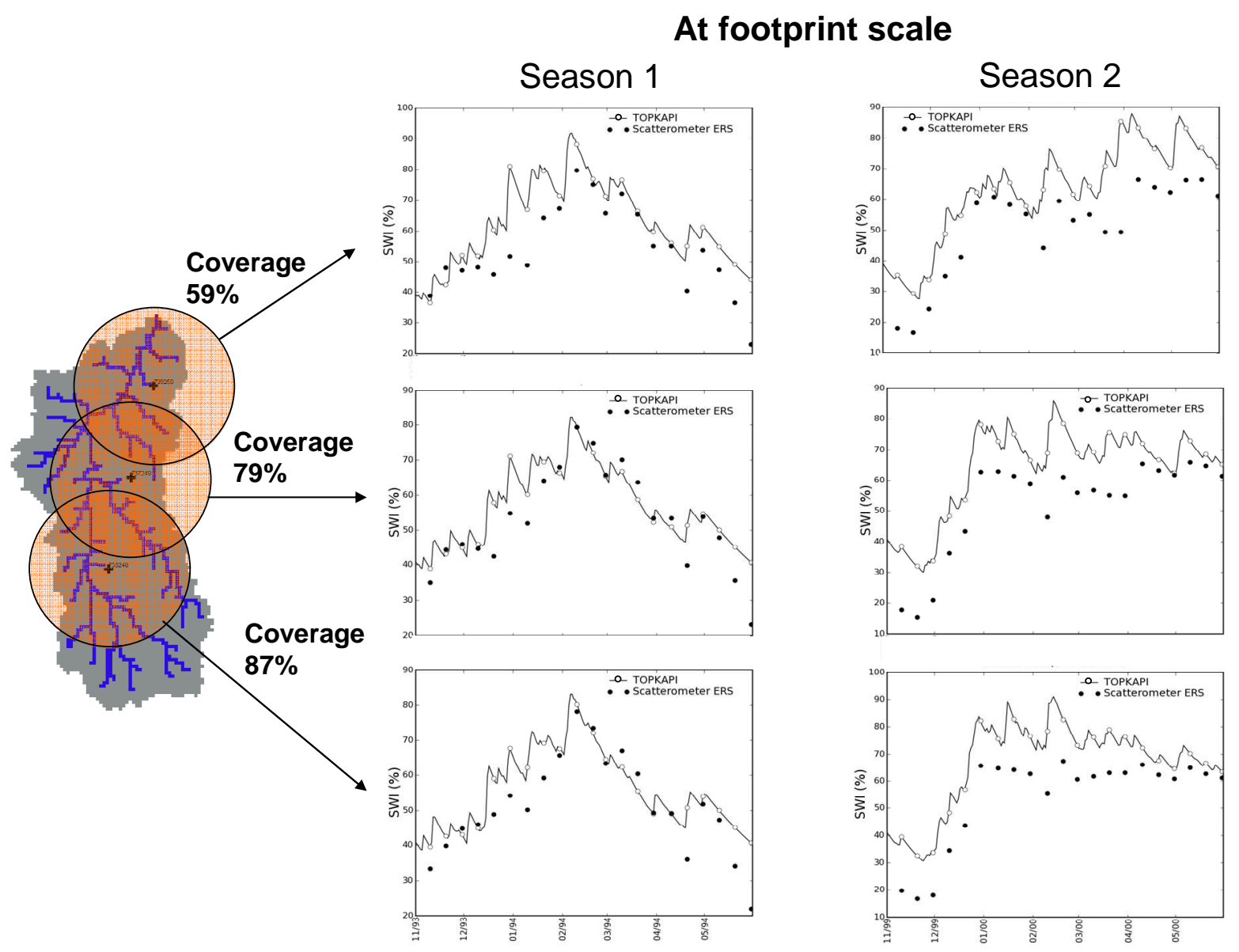

Fig. 7. Comparison of the modelled and remotely sensed Soil Water Index (SWI) at the scatterometer footprint scale.

two compared approaches have their own uncertainties that potentially lead to explain this bias.

\subsubsection{Uncertainties associated with hydrological modelling}

The results of the calibration showed that the values of the parameters of the TOPKAPI can be estimated a priori with a good reliability from information about the topography and the soil properties associated to parameter tables from the literature. The two exceptions were the channel roughness, multiplied by a factor 1.7 to get the right flow timing, and the hydraulic conductivity at saturation, which had to be multiplied by a factor of 60 , instead by a factor of 10 as suggested by Liu and Todini (2002), to account for macropores and preferential paths in the horizontal direction.

The increase of the channel roughness value $n_{c}$ is clearly due to the uncertainty of the DEM that does not reflect precisely the slopes of the drainage network that are particularly flat in the lower part of the catchment. Obviously one can argue that the multiplying factor of $K_{s}$ is not physically realistic. However, one has to be aware that the values of $K_{s}$ estimated a priori were derived from Green-Ampt infil- tration model tables that are associated with the local scale of a column of soil and for vertical infiltration fluxes. The alternative behaviour of the horizontal hydraulic conductivity has already been reported in the literature, particularly by the developers and users of TOPMODEL (Beven and Kirkby, 1979; Beven, 1997) and is mainly attributed to the fact that the lateral fluxes controlled by the topography are, in the subsurface, likely to occur in preferential paths (macropores, root pipes, soil cracks etc.). The calibration procedure tends to show that rapid flows in preferential paths are effectively dominant in the Liebenbergsvlei catchment. Another reason might be that the production of runoff can also be due to infiltration excess mechanisms (or Hortonian processes). Such processes are indeed likely to occur especially in semi-arid areas, as in the Liebenbergsvlei catchment. The difficulty of the model to respond to observed precipitation in the beginning of the wet season is probably linked to the production of Hortonian runoff, when the soils are dry and potentially crusted and the vegetation is not fully developed. However, the assumption of the predominance of subsurface flows and the associated saturation excess runoff production 


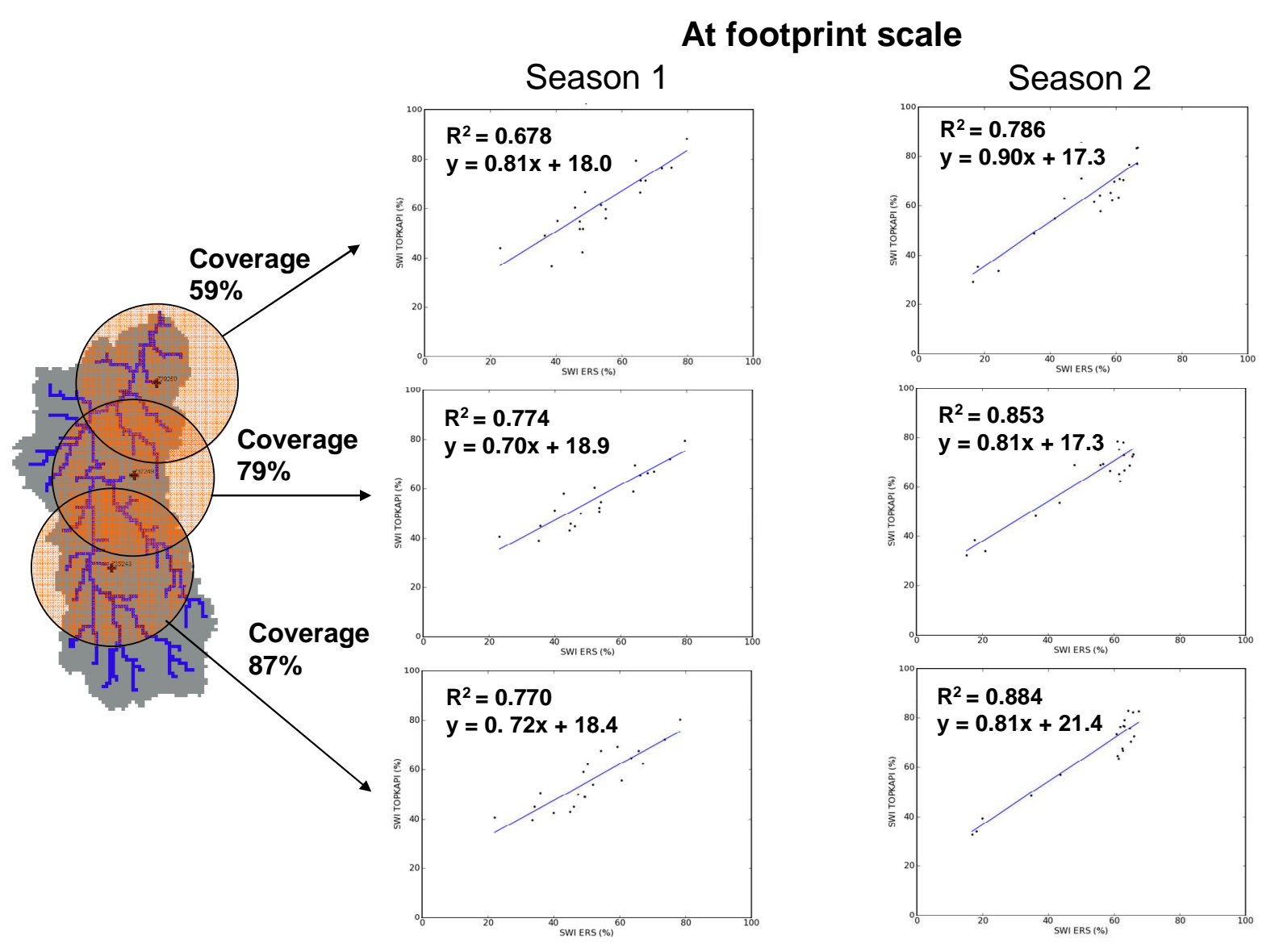

Fig. 8. Comparison of the modelled and remotely sensed Soil Water Index (SWI) at the scatterometer footprint scale (Scatter plots and regression equations).

seems to be realistic in the area for the major part the season. Some field experiments have been conducted at the hillslope scale in the region which tend to confirm that saturation excess production of runoff is predominant (Colin Everson, 2007; personal communication). These experiments suggest that the TOPKAPI hypothesis and the calibrated hydraulic conductivity are quite realistic on the Liebenbergsvlei catchment. It is also worth noting that a part of this increase of the hydraulic conductivity could be explained by the precision of the DEM: (i) in terms of resolution, since the $1 \mathrm{~km}$ resolution used here has been identified by Martina (2004) as the upper limit of physical scale above which the TOPKAPI model parameters no longer match the physics and also (ii) in terms of precision of the cell heights and corresponding slopes, that can have a strong influence on the parameter values (the reader is referred to Wechsler et al., 2007 for an interesting review of the hydrological model uncertainties associated with a DEM).

Generally speaking, it is accepted that there is uncertainty in the definition of a unique set of optimal parameters. The optimal parameter set calibrated on Season 1 gives relatively poor results when used in the verification process to simu- late discharges of season 2. The low performances of the model applied on season 2 can be attributed to the arbitrary choice of the initial soil moisture, the Hortonian processes that may have a longer influence for season 2 than season 1 . But a more probable reason is that the calibration conducted on station 1 in season 1 only has few chances to give a robust representation of the mean behaviour of the catchment over a long period, especially on the Liebenbergsvlei catchment where rainfall and runoff are subject to a strong inter-annual variability.

In order to figure out how the choice of the parameters' values can influence the results of the comparison of the SWI, Fig. 9 shows for season 1 the impact on the simulated discharge and SWI of a change in the values of the two main parameters influencing the runoff and the soil moisture production in the model. In association with Fig. 9, in Table 4 are reported the values of the criteria characterizing (i) the model performance according to the discharge and (ii) the comparison of the simulated SWI with the remotely sensed SWI. This sensitivity analysis shows by examining the responses, that of the values of the parameters influencing the discharge simulation: $K_{S}$ mainly influences the volume of 
Table 4. Sensitivity analysis on the effect of the parameters $K_{S}$ and $L$ on the simulated discharge and SWI. The Nash efficiency is computed on the calibration period over the subcatchment. The coefficient of determination $R^{2}$ and the regression equation are computed by comparing the simulated and the remotely sensed SWI. This table is associated with Fig. 9 that shows the corresponding curves of simulated discharge and soil moisture.

\begin{tabular}{cccccc}
\hline & Nash $Q$ period1 subcatchment & $R^{2}$ SWI period1 catchment & \multicolumn{2}{c}{$\begin{array}{c}\text { Regression line SWI } \\
y=a x+b\end{array}$} \\
& & & $a$ & $b$ \\
\hline & 20 & 0.600 & & 0.81 & 16.4 \\
$\operatorname{fac}_{K_{S}}$ & 60 (optimal) & 0.759 & 0.780 & 0.78 & 17.3 \\
& 80 & $\mathbf{0 . 7 8 8}$ & 0.771 & 0.75 & 18.1 \\
& 100 & 0.605 & 0.759 & 0.72 & 18.7 \\
& 0.6 & 0.227 & 0.737 & 0.88 & 19.2 \\
\hline $\operatorname{fac}_{L}$ & 0.8 & 0.669 & 0.629 & 0.82 & 14.2 \\
& 1 (optimal) & $\mathbf{0 . 7 8 8}$ & 0.72 & 0.75 & 18.1 \\
& 1.2 & 0.755 & 0.759 & 0.68 & 21.4 \\
& 1.4 & 0.744 & 0.765 & 0.62 & 24.1 \\
\hline
\end{tabular}
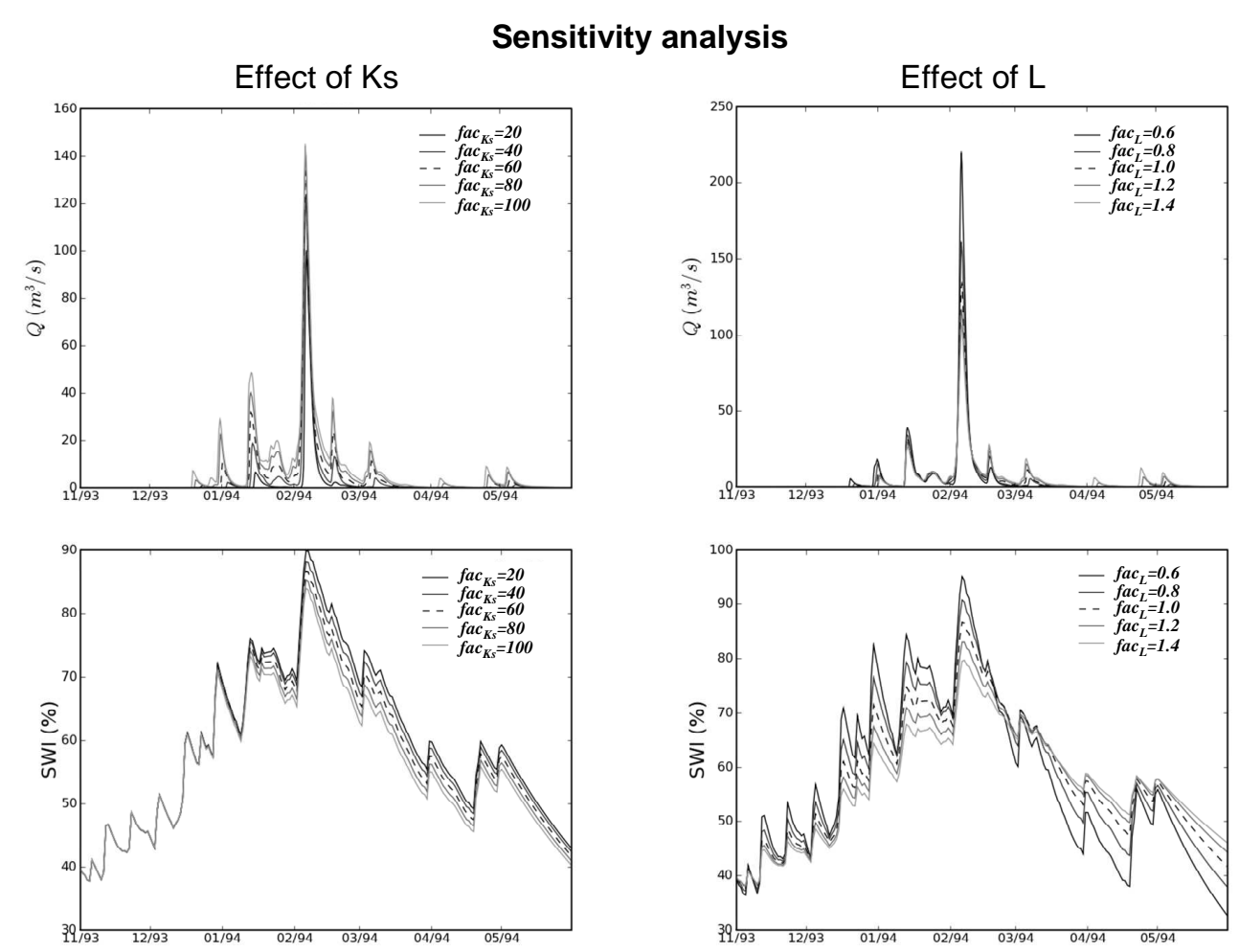

Fig. 9. Sensitivity analysis on the effect of the parameters $K_{S}$ and $L$ on the simulated discharge and SWI. This Figure is associated with Table 4 in which are reported the criteria characterizing (i) the model performance according to the discharge and (ii) the comparison of the simulated SWI with the remotely sensed SWI.

runoff, while $L$ mainly influences the values of the main peaks of discharge. The modelled soil moisture is also naturally influenced by the parameter values. The soil depth $L$ mainly controls the variability of the soil moisture and both $L$ and $K_{s}$ influence the bias value. But, whatever the val- ues of the parameters, the correlation between the modelled and remotely sensed soil moisture remains fair $\left(R^{2}\right.$ always higher than 0.6). It means that, even if there is an uncertainty in the parameter values, the general conclusions of the study remain unchanged. 


\subsubsection{Uncertainties associated with remote sensing}

The soil moisture retrieval method from the ERS scatterometer data is from its conception a change detection method which compares individual backscatter measurements to seasonally varying minimum and maximum backscatter reference values observed in long time series (Wagner et al., 1999a, b, c). The retrieved absolute soil moisture values thus depend on the assumptions about which soil moisture states are represented by the two backscatter reference values. The standard assumption for the thin remotely sensed surface layer $\left(m_{s}\right)$ is that minimum backscatter represents a completely dry soil and maximum backscatter water saturated soil (Wagner et al., 1999b). For the soil profile (SWI) minimum backscatter is in general related to a soil with water content at wilting point and maximum backscatter to a soil with a soil moisture content halfway between field capacity and total water capacity (Wagner et al., 1999c). The validity of these assumptions depends on the weather conditions during the reference period and the regionally varying climate. Therefore, the absolute values of the scatterometer soil moisture products ( $m_{s}$ and SWI) are deemed less reliable than the observed temporal trends. This notion was further corroborated by the results of this study. In fact, in most studies the scatterometer data are scaled to fit the reference soil moisture data best (Drusch et al., 2004; Pellarin et al., 2006).

Despite the uncertainties of each one of the approaches, that explain the bias identified in the comparison between the modelled and remotely sensed soil moisture, the study shows that there is a good correspondence in the dynamic of the soil moisture between the two independent soil moisture estimates. One might therefore question the reason for such a good correspondence. This is likely due to three main reasons:

1. The Soil Water Index is considered in the present study, meaning the relative water content along the soil depth. Many studies focus on vertical transfers (Soil Vegetation Atmosphere Transfer model) but ignore the lateral transfers (horizontal subsurface flows) that occur in the soil layer and partly control the soil moisture. In the present study, the lateral transfers are explicitly modelled by the TOPKAPI model to represent the subsurface flow processes. The study shows the benefit of using a distributed hydrological model that is able to explicitly represent the horizontal transfers in the soil in order to spatially redistribute modelled soil moisture.

2. The scatterometer estimations are sensitive to the vegetation and are better in less vegetated regions (Wagner et al., 1999b). In the Liebenbergsvlei, the grassland and cropland surfaces are likely to result in reliable estimates of soil moisture from this source.

3. The raingauge network is characterized by a very high spatial density of well calibrated pluviometers that give a reliable estimation of the precipitation amount at the catchment scale.

\subsection{Perspective}

The results obtained at this stage are very encouraging for (i) hydrological modelling and the possibility of using remotely sensed soil moisture to validate the models and also to initialize them; assimilation of the remotely sensed soil moisture data into hydrological models during simulations is also an exciting possibility, (ii) remote sensing and the possibility of using physically based hydrological models to validate and disaggregate the soil moisture estimations down to fine spatial scales.

Further research will aim to improve the modelling of the vertical fluxes that explicitly represent the vertical water transfers in the soil and will allow direct comparison between the remotely sensed soil moisture at the surface (first $5 \mathrm{~cm}$ of soil) without being dependent on the conceptual infiltration model used in the present study to infer the soil moisture profile from the surface remotely sensed soil moisture. Such a complete physically based model should help to better understand the processes that control the soil moisture patterns at regional scale and will be applied as a physically based soil moisture back-calculation and disaggregation tool.

Acknowledgements. This research was funded by the Water Research Commission (South Africa) and also formed part of the TIGER SHARE program initiated by the European Space Agency. Supplementary support was provided by the collaboration project between France and South Africa, SAFeWater, and the project GLOBESCAT funded by the Austrian Science Fund. The authors also want to thank the referees for the careful, thorough, insightful and helpful criticism of the first draft of the paper, which caused us to go back and question some of the fundamentals of the TOPKAPI model as well as revise and justify our judgements.

Edited by: L. Pfister

\section{References}

Beven, K.: TOPMODEL: a critique, Hydrol. Process., 11(9), 10691086, 1997.

Beven, K. and Kirkby, M.: A physically-based variable contributing area model of basin hydrology, Hydrol. Sci. Bull., 24, 43-69, 1979.

Biftu, G. F. and Gan, T. Y.: Semi-distributed, physically based, hydrologic modeling of the Paddle River Basin, Alberta, using remotely sensed data, J. Hydrol., 244, 137-156, 2001.

Blyth, E.: Modelling soil moisture for a grassland and a woodland site in south-east England, Hydrol. Earth Syst. Sci., 6(1), 39-47, 2002.

Brooks, R. H. and Corey, A. T.: Hydraulic properties of porous media, Hydrology papers, No. 3, Colorado State University, Colorado, 1964.

Bruckler, L. and Witono, H.: Use of remotely sensed soil moisture content as boundary conditions in soil-atmosphere water trans- 
port modeling. 2. Estimating soil water balance, Water Resour. Res., 25, 2437-2447, 1989.

Ceballos, A., Scipal, K., Wagner, W., and Martínez-Fernández, J.: Validation of ERS scatterometer-derived soil moisture data over the central part of the Duero Basin, Spain, Hydrol. Process., 19, 1549-1566, doi:10.1002/hyp.5585, 2005.

Chow, V. T., Maidment, D. R., and Mays, L. R.: Applied Hydrology, McGraw-Hill, New York, 1988.

Crow, W. T. and Zhan, X.: Continental-scale evaluation of remotely sensed soil moisture products, IEEE Geosci. Remote Sens. Letters, 4(3), 451-455, 2007.

Dirmeyer, P. A., Guo, Z. C., and Gao X.: Comparison, validation, and transferability of eight multiyear global soil wetness products, J. Hydrometeorol., 5(6), 1011-1033, 2004.

De Lannoy, G. J. M., Verhoest, N. E. C., Houser, P. R., Gish, T. J., and Meirvenne, M.: Spatial and temporal characteristics of soil moisture in an intensively monitored agricultural field (OPE3), J. Hydrol., 331, 719-730, 2006.

DLSI: A digital elevation model for South Africa, Directorate of Land Surveys and Information, South Africa, 1996.

Drusch, M., Wood, E. F., Gao, H., and Thiele, A.: Soil moisture retrieval during the Southern Great Plains Hydrology Experiment 1999: A comparison between experimental remote sensing data and operational products, Water Resour. Res., 40(2), W02504, doi:10.1029/2003WR002441, 2004.

Dunne, T.: Field studies of hillslope flow process, Hillslope Hydrology, edited by: Kirkby, M. J., Wiley, New York, 227-293, 1978.

Entekhabi, D., Rodriguez-Iturbe, I., and Castelli, F.: Mutual interaction of soil moisture state and atmospheric processes, J. Hydrol., 184, 3-17, 1996.

Gerald, C. F. and Wheatley, P. O.: Applied numerical analysis, 4th Ed., Addison-Wesley, 1992.

GLCC: Global Land Cover Characteristics. United States Geological Survey (USGS), http://edcdaac.usgs.gov/glcc, 1997.

Grayson, R. B, Western, A. W., and Chiew, F. H. S.: Preferred states in spatial soil moisture patterns: Local and nonlocal controls, Water Resour. Res., 33(12), 2897-2908, 1997.

Hébrard, O., Voltz, M., Andrieux, P., and Moussa, R.: Spatiotemporal distribution of soil surface moisture in a heterogeneously farmed Mediterranean catchment, J. Hydrol., 329, 110121,2006

Hodnett, M. G. and Bell, J. P.: Soil moisture investigations of groundwater recharge through black cotton soils in Madhya Pradesh, India, Hydrol. Sci. J., 31(3), 361-381, 1986.

Houser, P. R., Shuttleworth, W. J., Famiglietti, J. S., Gupta, H. V., Syed, K. H., and Goodrich, D. C.: Integration of soil moisture remote sensing and hydrologic modeling using data assimilation, Water Resour. Res., 34(12), 3405-3420, 1998.

Kostov, K. G. and Jackson, T. J.: Estimating profile soil moisture from surface layer measurements - a review, Proceedings of the international Society for Optical Engineering (SPIE), Orlando, 11-14 April, 125-136, 1993.

Liu, Z. and Todini, E.: Towards a comprehensive physically-based rainfall-runoff model, Hydrol. Earth Syst. Sci., 6(5), 859-881, 2002.

Liu, Z., Martina, M. L. V., and Todini, E.: Flood forecasting using a fully distributed model: application of the TOPKAPI model to the Upper Xixian catchment, Hydrol. Earth Syst. Sci., 9, 347-
364,2005

Maidment, D. R.: Handbook of hydrology, McGraw-Hill, New York, 1993.

Martina, M. L. V.: The distributed physically based modelling of the rainfall-runoff process, $\mathrm{PhD}$ Thesis, University of Bologna, 2004.

McKenzie, R. S. and Craig, A. R.: Evaporation losses from South African rivers, WRC Report no. 638/1/99, Pretoria, Water Research Commission (South Africa), 1999.

McNamara, J. P., Chandler, D., Seyfried, M., and Achet, S.: Soil moisture states, lateral flow, and streamflow generation in a semiarid, snowmelt-driven catchment, Hydrol. Process., 19, 40234038, 2005.

Merz, B. and Plate, E. J.: An analysis of the effect of spatial variability of soil and soil moisture on runoff, Water Resour. Res., 33, 2909-2922, 1997.

Midgley, D. C., Pitman, W. V., and Middleton, B. J.: Surface water resources of South Africa 1990, Water Research Commission, Report No. 298/2.2/94, 1994.

Ottlé, C. and Vidal-Madjar, D.: Assimilation of soil moisture inferred from infrared remote sensing in a hydrological model over the HAPEX-MOBILHY region, J. Hydrol., 158(3-4), 241-264, 1994.

Parajka, J., Naeimi, V., Blöschl, G., Wagner, W., Merz, R., and Scipal, K.: Assimilating scatterometer soil moisture data into conceptual hydrological models at the regional scale, Hydrol. Earth Syst. Sci., 10, 353-368, 2006, http://www.hydrol-earth-syst-sci.net/10/353/2006/.

Pauwels, V. R. N., Hoeben, R., Verhoest, N. E. C., De Troch, F. P., and De Troch, P. A.: Improvement of TOPLATS-based discharge predictions through assimilation of ERS-based remotely sensed soil moisture values, Hydrol. Process., 16, 995-1013, 2002.

Pellarin, T., Calvet, J.-C., and Wagner, W.: Evaluation of ERS scatterometer soil moisture products over a half-degree region in southwestern France, Geophy. Res. Lett., 33, L17401, doi:10.1029/2006GL027231, 2006.

Pellenq, J., Kalma, J., Boulet, G., Saulnier, G.-M., Wooldridge, S., Kerr, Y., and Chehbouni, A.: A disaggregation scheme for soil moisture based topography and soil depth, J. Hydrol., 276, 112127, 2003.

Reichle, R. H., Mc Laughlin, D. B., and Entekhabi, D.: Variational data assimilation of microwave radiobrightness observations for land surface hydrology applications, IEEE Trans. Geosci. Remote Sensing, 39(8), 1708-1718, 2001.

Rodriguez-Iturbe I.: Ecohydrology: a hydrologic perspective of climate-soil-vegetation dynamics, Water Resour. Res., 36, 3-9, 2000.

SIRI: Land Type Series. Department of Agriculture and Water Supply, Soil and Irrigation Research Institute, Memoirs on the Agricultural Natural Resources of South Africa, Pretoria, 1987.

Strahler, A. N.: Quantitative analysis of watershed geomorphology, Trans. Amer. Geophys. Union, 38, 913-920, 1957.

Vieux, B. E., Cui, Z., and Gaur, A.: Evaluation of a physics-based distributed hydrologic model for flood forecasting, J. Hydrol., 298, 155-177, 2004.

Wagner, W., Noll, G., Borgeaud, M., and Rott, H.: Monitoring soil moisture over the Canadian prairies with ERS scatterometer, IEEE Trans. Geosci. Remote Sens., 37(1), 200-216, 1999a.

Wagner, W., Lemoine, G., Borgeaud, M., and Rott, H.: A study of 
vegetation cover effects on ERS scatterometer data, IEEE Trans. Geosci. Remote Sens., 37(2), 938-948, 1999b.

Wagner, W., Lemoine, G., and Rott, H.: A method for estimating soil moisture from ERS scatterometer and soil data, Remote Sens. Environ., 70, 191-207, 1999c.

Wagner, W., Scipal, K., Pathe, C., Gerten, D., Lucht, W., and Rudolf, B.: Evaluation of the agreement between the first global remotely sensed soil moisture data with model and precipitation data, J. Geophys. Res. Atmos., 108(D19), 4611, doi:10.1029/2003JD003663, 2003.

Wagner, W., Blöschl, G., Pampaloni, P., Calvet, J.-C., Bizzarri, B., Wigneron, J.-P., and Kerr, Y.: Operational readiness of microwave remote sensing of soil moisture for hydrologic applications, Nord. Hydrol., 38(1), 1-20, 2007.

Walker, J. P., Willgoose, G. R., and Kalma, J. D.: One-dimensional soil moisture profile retrieval by assimilation of near-surface observations: a comparison of retrieval algorithms, Adv. Water Resour., 24, 631-650, 2001.
Wechsler, S. P.: Uncertainties associated with digital elevation models for hydrologic applications: a review, Hydrol. Earth Syst. Sci., 11, 1481-1500, 2007, http://www.hydrol-earth-syst-sci.net/11/1481/2007/.

Wesson, S. M. and Pegram, G. G. S.: Improved radar rainfall estimation at ground level, Nat. Hazards Earth Syst. Sci., 6, 323342, 2006,

http://www.nat-hazards-earth-syst-sci.net/6/323/2006/.

Western, A. W. and Blöschl, G.: On the spatial scaling of soil moisture, J. Hydrol., 217, 203-224, 1999.

Western, A. W., Grayson, R. B., and Blöschl, G.: Scaling of soil moisture: a hydrologic perspective, Ann. Rev. Earth Planet. Sci., 30, 149-180, 2002. 